\title{
Communication \\ Effects of Tungsten Disulphide Coating on Tapered Microfiber for Relative Humidity Sensing Applications
}

\author{
Norazida Ali ${ }^{1}\left(\mathbb{D}\right.$, Saaidal Razalli Azzuhri ${ }^{2} \mathbb{D}$, Md Ashadi Md Johari $^{3}$, Haroon Rashid ${ }^{1}(\mathbb{D}$, \\ Muhammad Imran Mustafa Abdul Khudus ${ }^{4}$, Mohd. Zulhakimi Ab. Razak ${ }^{5} \mathbb{D}$, Zhe Chen ${ }^{6}$, Norbahiah Misran ${ }^{1} \mathbb{D}$ \\ and Norhana Arsad 1,*(D)
}

check for updates

Citation: Ali, N.; Azzuhri, S.R.; Johari, M.A.M.; Rashid, H.; Khudus, M.I.M.A.; Razak, M.Z.A.; Chen, Z.; Misran, N.; Arsad, N. Effects of Tungsten Disulphide Coating on Tapered Microfiber for Relative Humidity Sensing Applications. Sensors 2021, 21, 7132. https:// doi.org/10.3390/s21217132

Academic Editor: Antonio Di Bartolomeo

Received: 30 August 2021

Accepted: 23 October 2021

Published: 27 October 2021

Publisher's Note: MDPI stays neutral with regard to jurisdictional claims in published maps and institutional affiliations.

Copyright: (c) 2021 by the authors. Licensee MDPI, Basel, Switzerland. This article is an open access article distributed under the terms and conditions of the Creative Commons Attribution (CC BY) license (https:// creativecommons.org/licenses/by/ $4.0 /)$.
1 Department of Electrical, Electronic and System Engineering, Faculty of Engineering and Built Environment, Universiti Kebangsaan Malaysia (UKM), Bangi 43600, Malaysia; p96194@siswa.ukm.edu.my (N.A.); haroon@ukm.edu.my (H.R.); bahiah@ukm.edu.my (N.M.)

2 Department of Computer System and Technology, Faculty of Computer Science and IT, University of Malaya, Kuala Lumpur 50603, Malaysia; saaidal@um.edu.my

3 Faculty of Engineering Technology, Universiti Teknikal Malaysia Melaka, Melaka 76100, Malaysia; ashadi@utem.edu.my

4 Department of Physics, Faculty of Science, University of Malaya, Kuala Lumpur 50603, Malaysia; m.imran.mustafa@um.edu.my

5 Institute of Microengineering and Nanoelectronics, Universiti Kebangsaan Malaysia (UKM), Bangi 43600, Malaysia; zul.hakimi@ukm.edu.my

6 Department of Optoelectronic Engineering, Jinan University, Road Huangpu, District Tianhe, Guangzhou 510632, China; thzhechen@jnu.edu.cn

* Correspondence: noa@ukm.edu.my

\begin{abstract}
Tungsten disulphide $\left(\mathrm{WS}_{2}\right)$ is a two-dimensional transition-metal dichalcogenide material that can be used to improve the sensitivity of a variety of sensing applications. This study investigated the effect of $\mathrm{WS}_{2}$ coating on tapered region microfiber (MF) for relative humidity (RH) sensing applications. The flame brushing technique was used to taper the standard single-mode fiber (SMF) into three different waist diameter sizes of MF 2, 5, and $10 \mu \mathrm{m}$, respectively. The MFs were then coated with $\mathrm{WS}_{2}$ via a facile deposition method called the drop-casting technique. Since the MF had a strong evanescent field that allowed fast near-field interaction between the guided light and the environment, depositing $\mathrm{WS}_{2}$ onto the tapered region produced high humidity sensor sensitivity. The experiments were repeated three times to measure the average transmitted power, presenting repeatability and sensing stability. Each MF sample size was tested with varying humidity levels. Furthermore, the coated and non-coated MF performances were compared in the RH range of 45-90\% $\mathrm{RH}$ at room temperature. It was found that the $\mathrm{WS}_{2}$ coating on $2 \mu \mathrm{m}$ MF had a high sensitivity of $0.0861 \mathrm{~dB} / \% \mathrm{RH}$ with linearity over $99 \%$. Thus, MF coated with $\mathrm{WS}_{2}$ encourages enhancement in the evanescent field effect in optical fiber humidity sensor applications.
\end{abstract}

Keywords: tapered microfiber; humidity sensor; transition-metal dichalcogenide; tungsten disulphide $\left(\mathrm{WS}_{2}\right)$

\section{Introduction}

Silica fiber has received significant attention due to various applications in laser technology [1-3], sensor technology [4,5], plasmonic devices [6,7], telecommunications devices [8], and other applications. Moreover, due to recent technological development, silica fiber has experienced changes in structure, size, and composition, increasing its performance [9-11]. Hence, silica fiber has been used in critical areas for sensing purposes, such as the biomedical and chemical industries [12-14]. The size of silica fiber is the center of the discussion, as it can be manipulated and reduced to the micro-scale. This new development may increase the potential of silica fiber to be used widely and for numerous applications [15]. One techniques known as flame brushing can taper and reduce the silica 
fiber size down to the micro-region by heating and pulling using sufficient temperature flame $[16,17]$. The micro-silica fiber, better known as MF or tapered fiber, has a unique character due to its diameter and high index contrast between the core of the fiber and the air [18]. MF is the best choice in optical sensing applications based on the principle of the evanescent field, where strong interactions occur between the MF medium and its surroundings. This principle has been a significant advantage of MF, potentially being used in a limited area with high performances.

The MF structures used for relative humidity sensors can be classified into resonator and non-resonator types. A resonator is an advanced structure based on a closed-loop configuration that uses a large evanescent field created from self-coupling light and overlapping condition. This configuration enables the evanescent field to interact with the surrounding environment of the sensing region. As a result, the collected transmitted light is interpreted as the changed output power for sensing purposes. There are a few resonator-based structures, including the MF loop resonator (MLR) [19], the MF coil resonator (MCR) [20], the MF knot resonator (MKR) [21], and the whispering gallery mode resonator (WGMR) [22]. The working principle of the resonator-based humidity sensor is that the resonance wavelength is changed with the variation of humidity concentration. Besides sensitivity and linearity parameters, other sensing characteristics of resonators have been studied for the humidity sensors: intensity variation, wavelength shift, and Q-factor.

Unlike the resonator, the configuration of a non-resonator MF's structure is straightforward and has been extensively used [23,24]. Besides, it has various forms, such as functional material coated sensors, Mach-Zehnder interferometer (MZI)-based sensors, micro-probes/nano-probes, grating-based sensors, and coupling-based sensors. For functional material coated sensors, the tapered region surface is coated with high refractive index material to create the functionality in humidity sensing to sustain the ability of waveguiding [25].

Two-dimensional (2D) transition metal dichalcogenides (TMDs) have recently piqued the interest of researchers due to their unique electrical, optical, chemical, and thermal properties [26-28]. Among TMDs, tungsten disulphide $\left(\mathrm{WS}_{2}\right)$ has shown good potential for humidity sensing [29]. Numerous studies on humidity sensors that use 2D nanostructurebased materials coating as sensitivity catalysts have been reported recently [30-33].

In this work, the effects of $\mathrm{WS}_{2}$ coating on various waist diameters of MF using a facile and cost-effective method known as the drop-casting technique were explored for relative humidity sensing applications. Before that, using the flame brushing technique, we managed to form three sizes of tapered fiber region, i.e., 2, 5, and $10 \mu \mathrm{m}$. These MFs were then coated with $\mathrm{WS}_{2}$ and tested in humidity ranging from $45 \%$ to $90 \%$ for sensing purposes. The characterization of coated MFs was done by using a tunable laser source and optical power meter. The performances of coated MFs for the different tapered region in humidity sensing were evaluated and compared.

\section{Fabrication and Preparation of Tapered Microfiber Sensor}

Figure 1 shows the schematic of the fabrication technique of the MF by means of a flame brushing method. The MF was fabricated from standard $125 \mu \mathrm{m}$ SMF-28 using Programmable Logic Controller (PLC) stepper motor stages to pull the fiber while the flame from the torch moved to heat the stripped fiber. First, the outer plastic of the fiber was removed and the buffer was stripped, as shown in Figure 2. The fiber was then finely placed on the holder for the tapering process. The stripped area was heated gradually by manipulating the flame temperature, and the fiber was pulled from both sides to complete the process. 


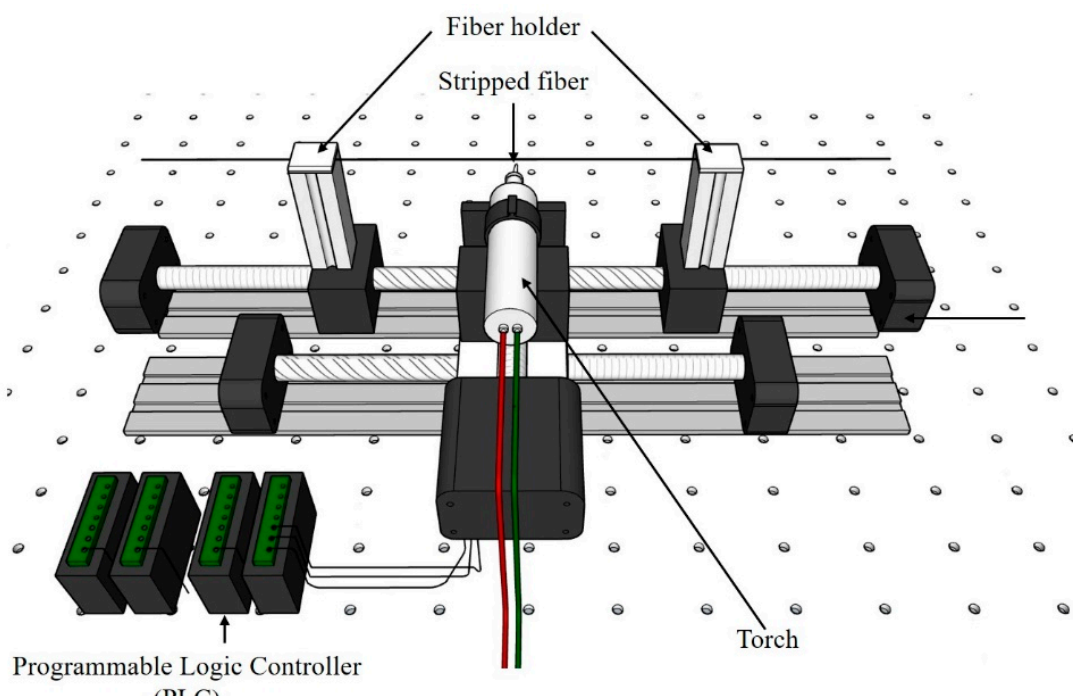

(PLC)

Figure 1. Schematic of the MF taper fabrication setup.

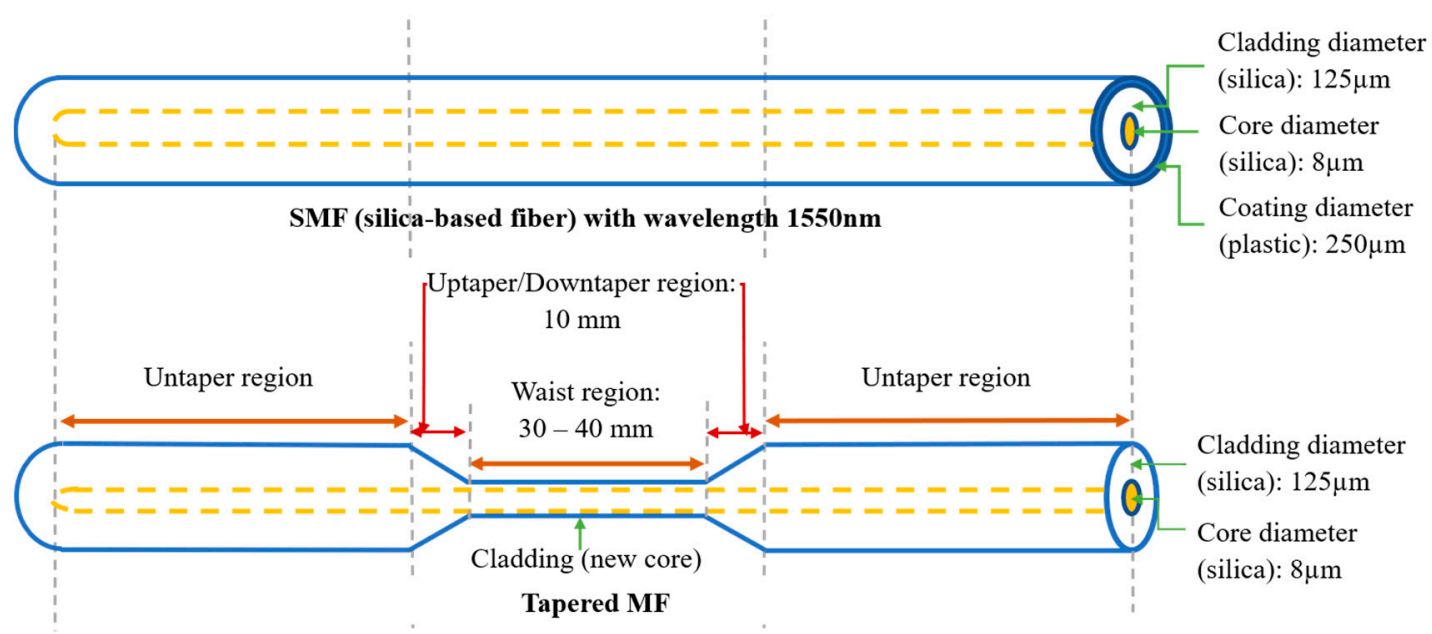

Figure 2. SMF before and after tapering process.

The MFs were then placed on glass slides and measured under a microscope to ensure the desired tapered region diameter depicted in Figure 3. After that, each MF sample was placed on a stage for the deposition process. The coating material, $\mathrm{WS}_{2}$ prepared in solution, was purchased from the Graphene Supermarket, which is practical for the SMF coating process. The MFs were coated at the tapered region with $10 \mu \mathrm{L}$ of $\mathrm{WS}_{2}$ using the drop-casting technique and left in ambient environment for two hours to obtain a uniform layer formation on the tapered MF surface. The coated MFs were tested on a few humidity levels for sensing purposes.

The size of the MF was determined by the time consumed by the heating process during the tapering procedure. The duration of tapering time is proportional to the size of the MF. Figure 4 demonstrates the characterization of MF in two parameters: waist diameter $\mathrm{D}_{\mathrm{w}}$ and neck-to-neck length $\mathrm{L}_{\mathrm{w}}$. The $\mathrm{D}_{\mathrm{w}}$ is determined as the size of produced $\mathrm{MF}$, which were 2,5 , and $10 \mu \mathrm{m}$ with the waist-length range of about 30 to $40 \mathrm{~mm}$. 


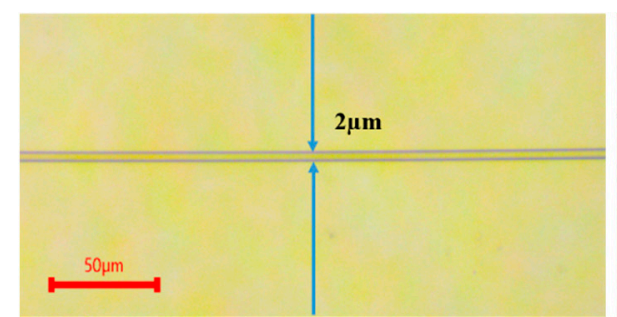

(a)

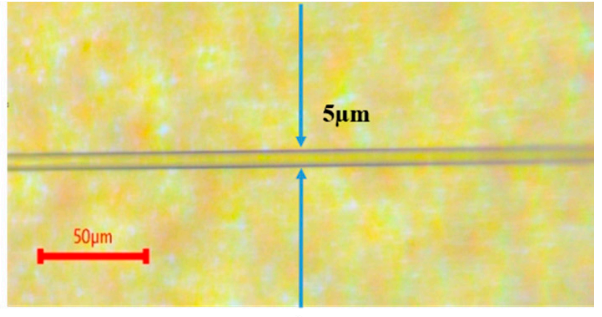

(b)

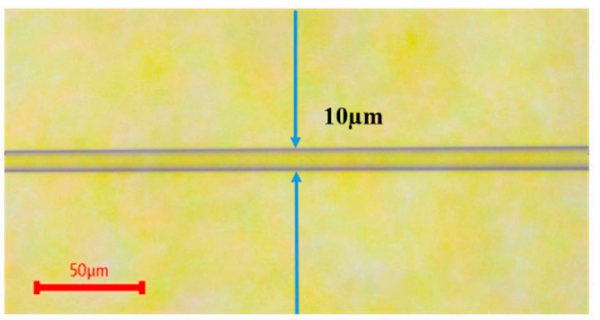

(c)

Figure 3. Microscopic image for tapered region MF with $2 \mu \mathrm{m}(\mathbf{a}), 5 \mu \mathrm{m}(\mathbf{b})$, and $10 \mu \mathrm{m}$ (c) diameter.
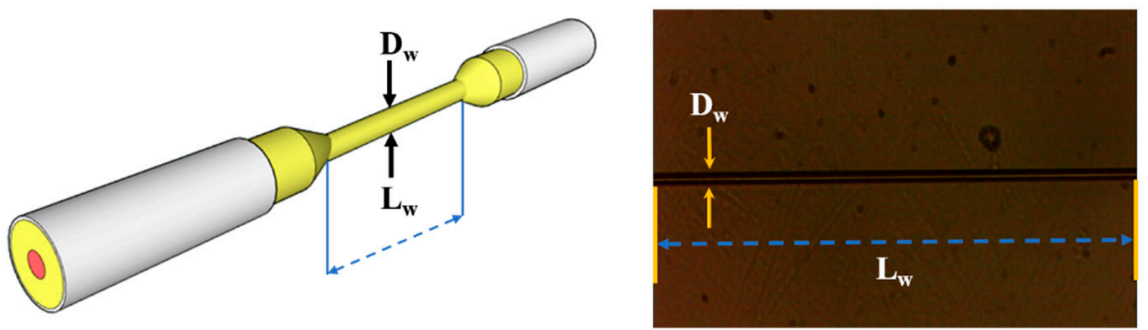

(a)
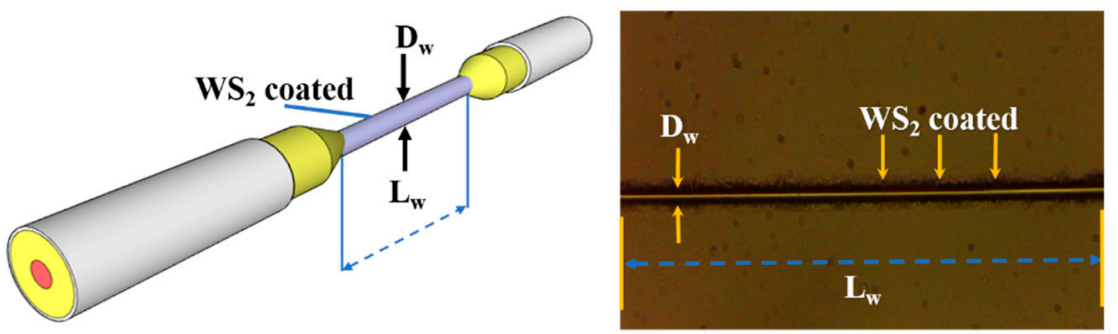

(b)

Figure 4. Microscopic images of MF structure (a) before coated and (b) after coated with $\mathrm{WS}_{2}$.

\section{Experimental Setup}

The performances of MF before and after $\mathrm{WS}_{2}$ coatings were compared. Figure 5 shows the experimental setup to investigate the performance of coated MF towards a different level of relative humidity percentage. Three differently coated MFs, i.e., 2, 5, and $10 \mu \mathrm{m}$, were placed inside the sealed chamber, whose ends were connected to the tunable laser source (TLS) and to the optical power meter (OPM). The chamber was also connected to a commercial hygrometer sensor (RS 1365) to monitor relative humidity levels. The experiment was performed at ambient temperature $\left(25^{\circ} \mathrm{C}\right)$ under an atmospheric pressure of $1.0 \mathrm{~atm}$. The relative humidity was varied from $45 \%$ to $90 \% \mathrm{RH}$ by using sodium hydroxide $(\mathrm{NaOH})$ mixed with a drop of water inside the chamber.

The TLS (ANDO AQ4321D) at $1550 \mathrm{~nm}$ was used as an input, and the OPM (THORLABS S145C) was used to observe the output power simultaneously. Each coated MF of different sizes was repeatedly tested for three cycles to reduce the random errors during the experiment. 


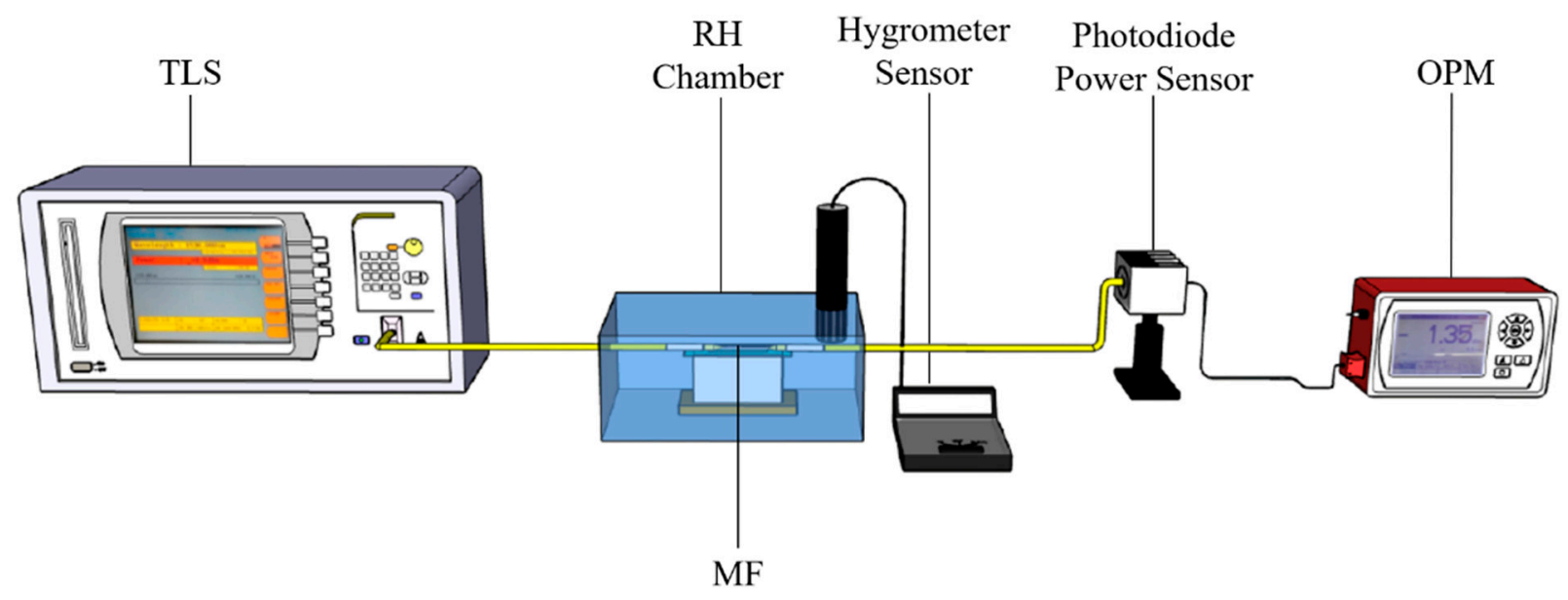

Figure 5. Experimental setup for MF RH sensing.

\section{Sensing Mechanism}

Despite tapered MF-based sensors having a simple form and being low cost, the detecting mechanism renders the RH sensor highly subject to light transmitted changes and fiber loss. The tapered MF sensing mechanism has relied on the variation of light intensity and transmission scheme, which can be used to evaluate the performance of the $\mathrm{RH}$ sensor. This sensor operates strongly dependently on MF that guides light through the tapered region (sensing area) and the interaction of evanescent field outside the fiber. It can be found that due to the strong evanescent field, the MF is extremely sensitive to the change in the surrounding environment, including temperature and $\mathrm{RH}$.

For comparison, the actual $\mathrm{RH}$ level reading surrounding the tapered fiber inside the chamber was also measured using a hygrometer sensor as a reference. The changes in the surrounding environment caused by the presence of water vapor will result in the variation of the output transmitted power of the tapered $\mathrm{MF}$, making it suitable to be used as a moisture sensor. The output transmitted power is identified by the modulation of light intensity according to the interaction between evanescent field absorption and the propagated light signal.

However, the tapered MF RH sensor found some difficulties in measuring the accurate value of sensing parameters since it is influenced by the fluctuations from the surrounding environment. Therefore, integrating the tapered MF with a coating material will improve the sensitivity of the RH sensor.

$W_{2}$ is among the TMDs that offers thermodynamic stability at room temperature, and that is capable of both absorption and desorption of water vapor. $\mathrm{WS}_{2}$ was deposited on the tapered MF as sensing material allowing for enhanced sensitivity of the RH sensor. When the sensor was exposed to water vapor, the tapered MF significantly interacted with the $\mathrm{WS}_{2}$, causing a change in fiber optical transmission at $1550 \mathrm{~nm}$ wavelength. As a result, even a tapered MF with a small waist diameter will achieve a high sensitivity RH sensor by enhancing evanescent field interaction between guided light and $\mathrm{WS}_{2}$ coating.

\section{Results and Discussion}

\subsection{Characterization of Tapered Microfiber}

The TLS was used to characterize the $\mathrm{WS}_{2}$-coated MF with a wavelength ranging from 1520 to $1620 \mathrm{~nm}$. This experiment used the range of wavelengths from 1550 to $1550.1 \mathrm{~nm}$ with an interval of $0.001 \mathrm{~nm}$. The OPM was used to collect the output power from the other end of the fiber. Figure 6 shows the transmission spectra produced by tapered MF with three different waist diameters $\left(\mathrm{D}_{\mathrm{w}}\right)$ and coated with $\mathrm{WS}_{2}$. The insertion loss from the $2 \mu \mathrm{m}$ coated MF was $-29.20 \mathrm{dBm}$, for the $5 \mu \mathrm{m}$ MF it was $-18.1 \mathrm{dBm}$, and for the $10 \mu \mathrm{m}$ MF it was $-18.9 \mathrm{dBm}$. From the results, 5 and $10 \mu \mathrm{m}$ coating MFs had similar insertion loss values, whereas the insertion loss of the $2 \mu \mathrm{m}$ MF was slightly lower. The size of 
non-coated MF affected the value of insertion loss. The coating diameter remained the same for all MFs: $<10 \mu \mathrm{m}$.

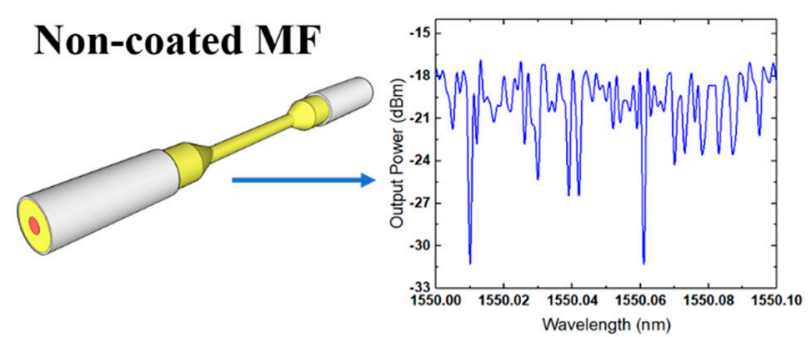

(a) $2 \mu \mathrm{m}$

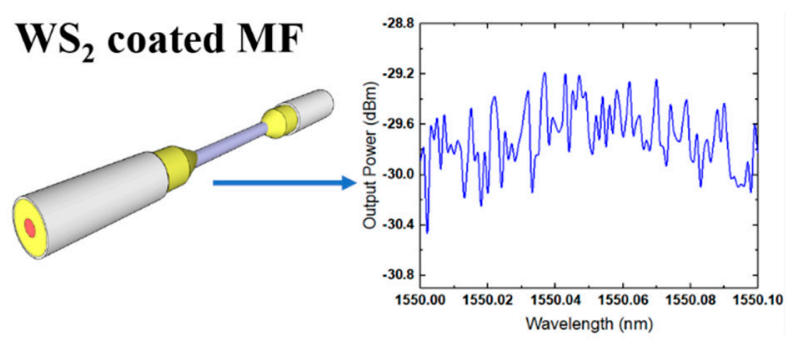

(d) $2 \mu \mathrm{m}$

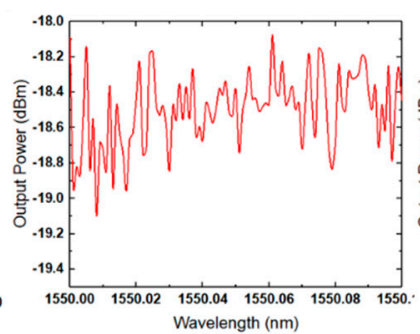

(b) $5 \mu \mathrm{m}$

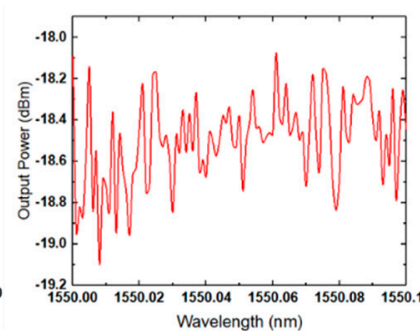

(e) $5 \mu \mathrm{m}$

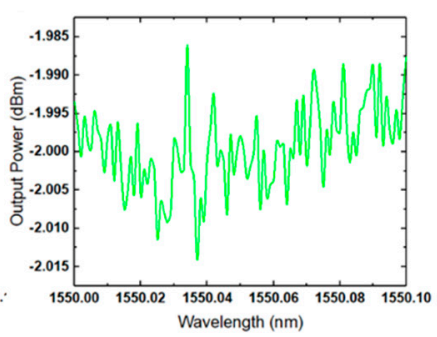

(c) $10 \mu \mathrm{m}$

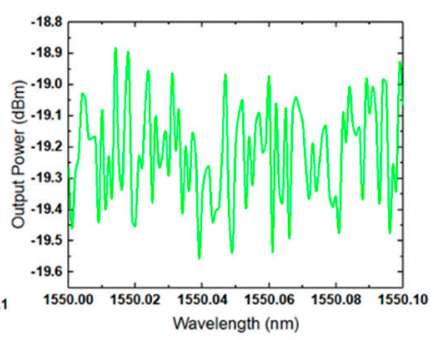

(f) $10 \mu \mathrm{m}$

Figure 6. Non-coated MF transmission modes $(\mathbf{a}-\mathbf{c})$ and coated MF transmission modes (d-f) of 2, 5, and $10 \mu \mathrm{m}$.

The transmission spectra for the non-coated MF of three different sizes are depicted in Figure 6a. The insertion loss from the $2 \mu \mathrm{m}$ non-coated MF was $-17.00 \mathrm{dBm}$; it was $-18.1 \mathrm{dBm}$ for the $5 \mu \mathrm{m} \mathrm{MF}$; and it was $-1.985 \mathrm{dBm}$ for the $10 \mu \mathrm{m} \mathrm{MF}$. For $2 \mu \mathrm{m}$ and $5 \mu \mathrm{m}$ non-coated MFs, the insertion loss values were lower than $10 \mu \mathrm{m}$. The MF guides light as a single-mode waveguide, with the evanescent field guided outside the MF. This evanescent field is affected not only by the operating wavelength and the surrounding medium, but also by the diameter of the fiber [34]. Therefore, the size of the MF is still the main contributing factor for the insertion loss value, even for a non-coated MF. The waist diameter size of the MF sensor corresponds to the output transmitted power value. A small diameter of MF decreases the refractive index of the fiber and allows the light travelling through it to be refracted outside. Consequently, the insertion loss of output power will increase as the MF diameter decreases. For sensing applications, the smallest diameter is crucial to allow more light to be refracted over microfiber boundaries and become a sensing mechanism. The more light refracts, the more sensitive it becomes.

\subsection{Structural, Morphological, and Compositional Analysis of $W_{2}$}

The morphological characteristics of the MF were analyzed using field emission scanning electron microscopy (FESEM). Figure 7a represents the surface morphology of $\mathrm{WS}_{2}$ coated (thin layer) on top of the MF waist region. The enlarged image of the $\mathrm{WS}_{2}$ can be seen in Figure 7b, which adhered to the MF surface with a diameter range of 400 to $600 \mathrm{~nm}$. The elemental compositional analysis and elemental distribution mapping were performed using energy-dispersive X-ray spectroscopy (EDX). Figure 7c represents EDX analysis of the $10 \mu \mathrm{m} \mathrm{WS}_{2}$-coated MF. The inset of Figure 7c tabulates the percentual weights and atomic percentages of the elemental compositions of materials. The presence of tungsten (W) and sulfur (S) confirms the successful deposition of sensitive sensing material $\left(\mathrm{WS}_{2}\right)$. Silicon $(\mathrm{Si})$, carbon $(\mathrm{C})$ and oxygen $(\mathrm{O})$ peaks arose from MF. The normalized S/W ratio was calculated to be 1.667 , which is evidence of non-stoichiometric $\mathrm{WS}_{2}$ presence. The deficiency of $\mathrm{S}$ atoms is attributed to the presence of $\mathrm{O}$ atoms from the environmental during the deposition process performed at room temperature. Figure $7 \mathrm{f}-\mathrm{i}$ represents the elemental distribution mapping of $\mathrm{Si}, \mathrm{W}, \mathrm{O}$ and $\mathrm{S}$, respectively. 


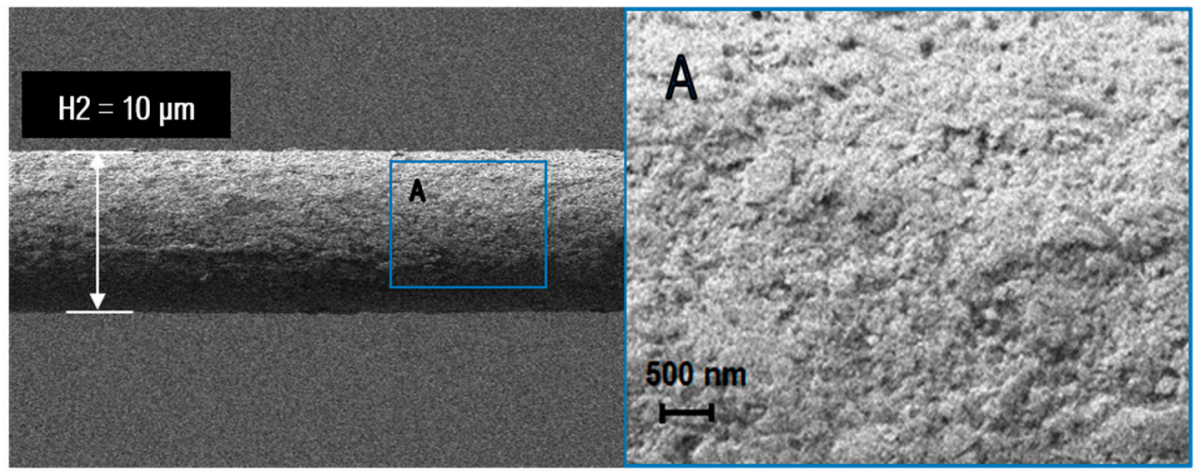

(a)

(b)

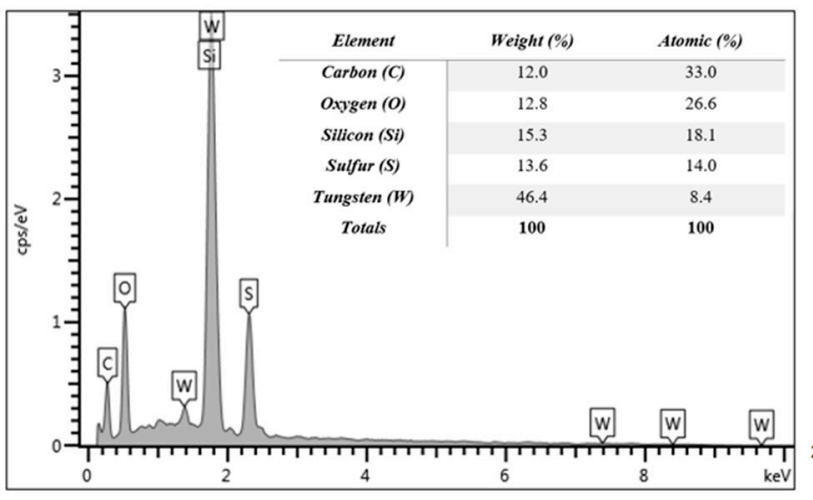

(c)

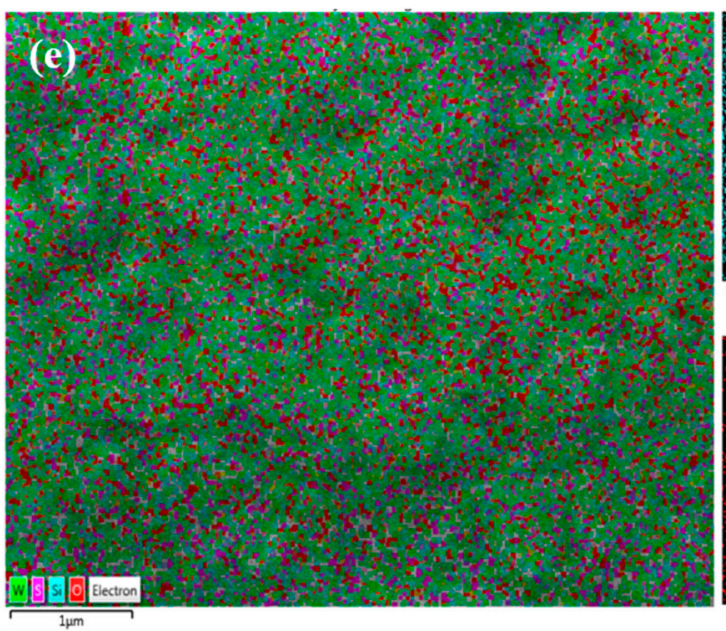

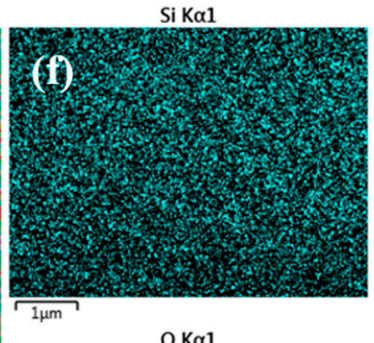

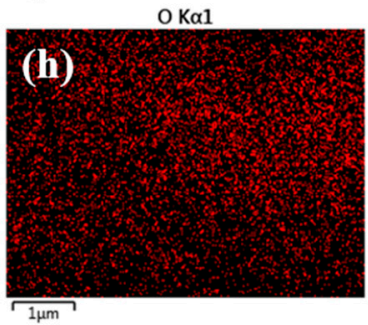

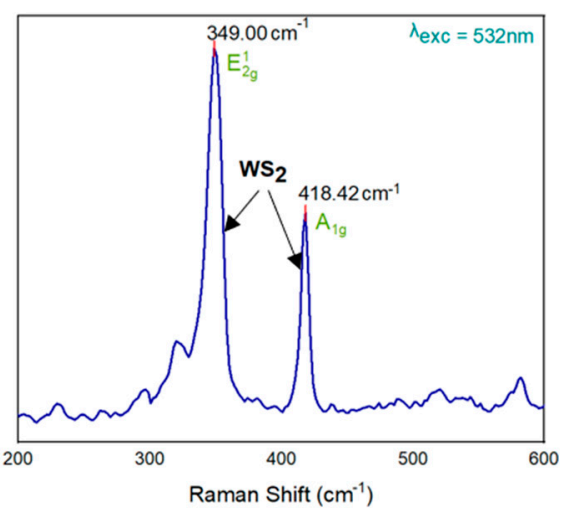

(d)
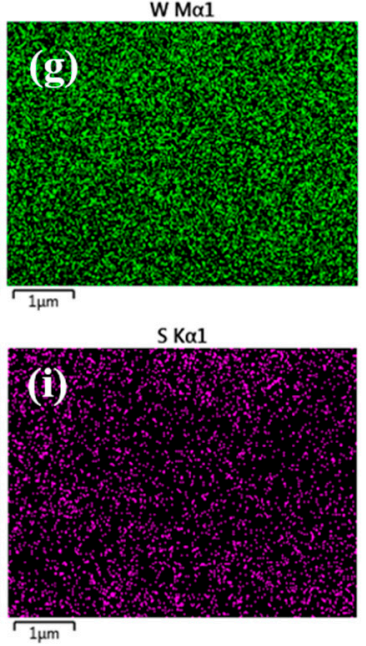

Figure 7. FESEM image of the MF coated with $\mathrm{WS}_{2}(\mathbf{a})$. An enlarged view of the region marked by a blue rectangle is $\mathrm{MF}$ coated with $\mathrm{WS}_{2}$ at 10,000 $\times$ magnification (b). EDX elemental spectrum and quantification results for tapered MF coated with $\mathrm{WS}_{2}$ (c). Raman spectra of $\mathrm{WS}_{2}$ coated on MF by drop-casting (d). EDX-elemental mapping on the tapered region of MF coated with $W_{2}(\mathbf{e})$. Silicon, (f) tungsten $(W)(\mathbf{g})$; oxygen $(\mathrm{O})(\mathbf{h})$, and sulfur (i) distribution mapping.

The structural properties of coated MF were obtained using Raman scattering analysis within the spectrum range from 330 to $450 \mathrm{~cm}^{-1}$. Figure $7 \mathrm{~d}$ divulges the bonding structure of the thin $\mathrm{WS}_{2}$ layer. Two dominant peaks are shown within the spectrum range. Both originated from an in-plane optical mode known as phonon mode $\left(\mathrm{E}^{1}{ }_{2 \mathrm{~g}}\right)$ and from an out-plane vibration mode caused by $S$ atoms, confirming the successful growth of $\mathrm{WS}_{2}$ on the MF surface. The lattice vibration is caused by the weak van der Waals interlayer forces. Both $E_{2 g}^{1}$ and $A^{1}$ modes are apparent at 349 and $418.42 \mathrm{~cm}^{-1}$, respectively. The 
separation $(\Delta)$ between two peaks $\left(\mathrm{E}^{1}{ }_{2 \mathrm{~g}}\right.$ and $\left.\mathrm{A}^{1} \mathrm{~g}\right)$ was calculated as $69.42 \mathrm{~cm}^{-1}$, which validates the presence of $\mathrm{WS}_{2}$ [35].

\subsection{The Performance of the RH Sensor}

Sensitivity and linearity values for three different sizes of coated and uncoated MFs are shown in Figure 8. Sensitivity is defined as the change in output power for each RH level [36]. Linearity is the interaction of output powers concerning each percentage of RH [37]. Figure 8 a shows the sensitivity and linearity results, among which $2 \mu \mathrm{m}$ coated MF recorded the highest values: $0.0861 \mathrm{~dB} / \% \mathrm{RH}$ for sensitivity and $99.8 \%$ for linearity. Figure $8 \mathrm{~b}$ represents the sensitivity and linearity values for non-coated MF. The $2 \mu \mathrm{m}$ non-coated MF had the highest performance parameters with a sensitivity of $0.0615 \mathrm{~dB} / \%$ $\mathrm{RH}$ and linearity of $99.6 \%$. The tapered regions of $5 \mu \mathrm{m}$ and $10 \mu \mathrm{m}$ show lower sensitivity and linearity than the $2 \mu \mathrm{m}$ tapered MF. The results for all parameters are tabulated in Table 1 . In both graphs, the $2 \mu \mathrm{m}$ coated MF shows the best performance for sensitivity and linearity. It is also shown to have more sensitivity towards a different level of humidity. Moreover, by coating the MF with $\mathrm{WS}_{2}$, the humidity sensor recorded higher sensitivity and linearity than the non-coated MF. These experiments show that $\mathrm{WS}_{2}$ has the potential to improve humidity sensing capabilities.

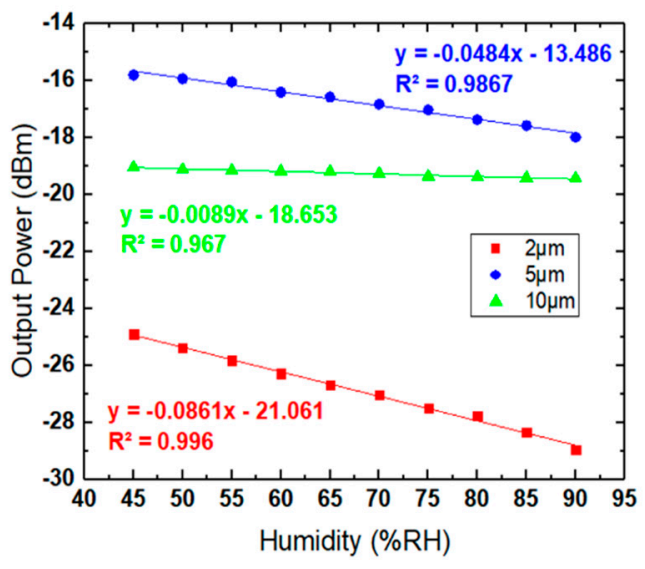

(a)

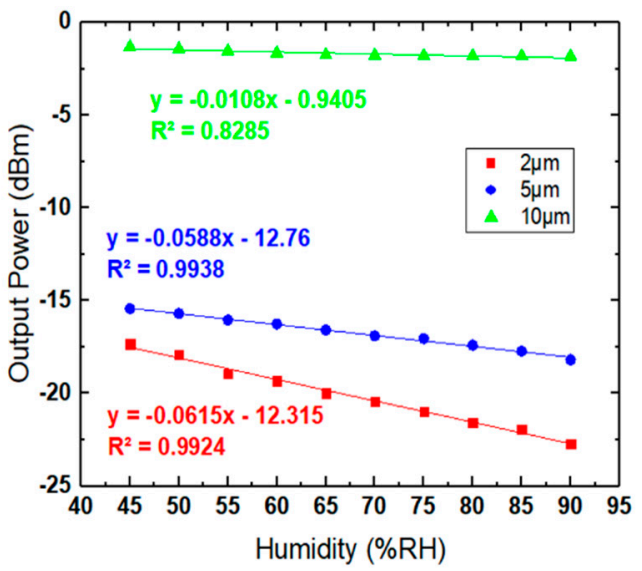

(b)

Figure 8. Transmitted power value for three different diameters of $\mathrm{WS}_{2}$ : (a) coated MFs and (b) non-coated MFs. Power varies with the percentage of humidity.

Table 1. Analysis of different diameters of $\mathrm{MF}$ with $\mathrm{WS}_{2}$ performance in humidity sensing activity.

\begin{tabular}{|c|c|c|c|c|c|c|}
\hline \multirow[b]{2}{*}{ Parameters } & \multicolumn{2}{|c|}{$2 \mu \mathrm{m}$} & \multicolumn{2}{|c|}{$5 \mu \mathrm{m}$} & \multicolumn{2}{|c|}{$10 \mu \mathrm{m}$} \\
\hline & $\begin{array}{c}\text { Non-Coated } \\
\text { MF }\end{array}$ & Coated MF & $\begin{array}{c}\text { Non-Coated } \\
\text { MF }\end{array}$ & Coated MF & $\begin{array}{c}\text { Non-Coated } \\
\text { MF }\end{array}$ & Coated MF \\
\hline Linearity (\%) & 99.6 & 99.8 & 99.3 & 99.3 & 91.0 & 98.3 \\
\hline Sensitivity $(\mathrm{dB} / \% \mathrm{RH})$ & 0.0615 & 0.0861 & 0.0484 & 0.0484 & 0.0108 & 0.0089 \\
\hline Linear Range (\% RH) & $45-90$ & $45-90$ & $45-90$ & $45-90$ & $45-90$ & $45-90$ \\
\hline
\end{tabular}

Figure 9 represents the repeatability results for coated and non-coated MF on all three diameter sizes. This process is vital to reduce random error in measurement, which affects the sensing process. For every MF condition, it was repeated three times with the same setup. The sensitivity and linearity were calculated to ensure that all data collection was always on track. The results show that the $2 \mu \mathrm{m}$ MF exhibited the best sensitivity toward RH changes for both coated and non-coated MFs, and among all the MF, the $2 \mu \mathrm{m}$ coated MF had the optimum RH sensing performance. 


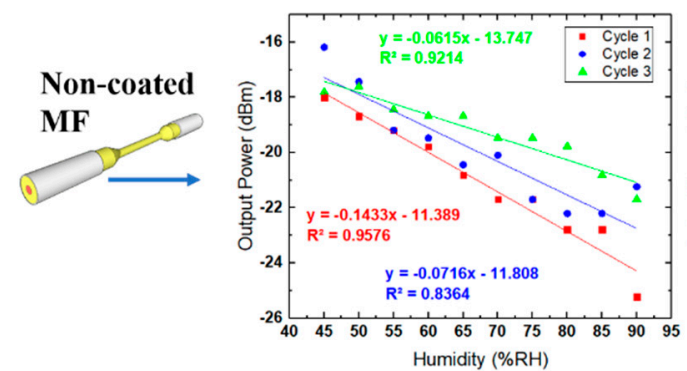

(a) $2 \mu \mathrm{m}$

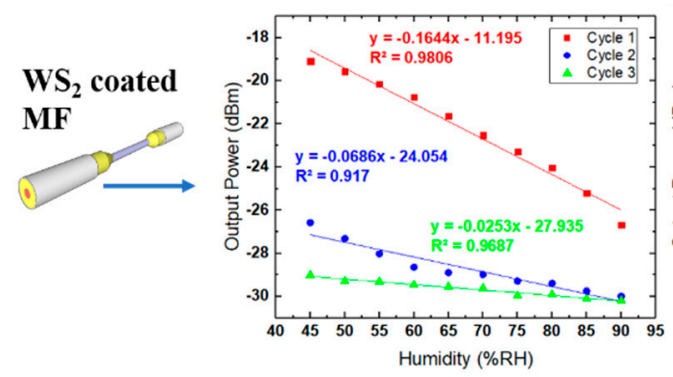

(d) $2 \mu \mathrm{m}$

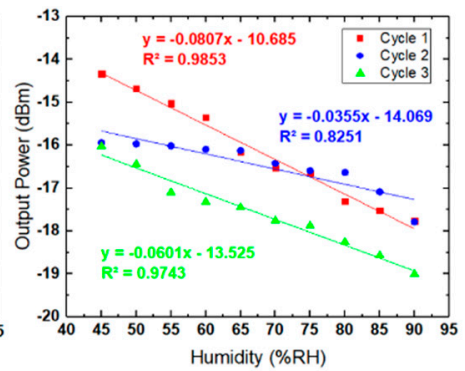

(b) $5 \mu \mathrm{m}$

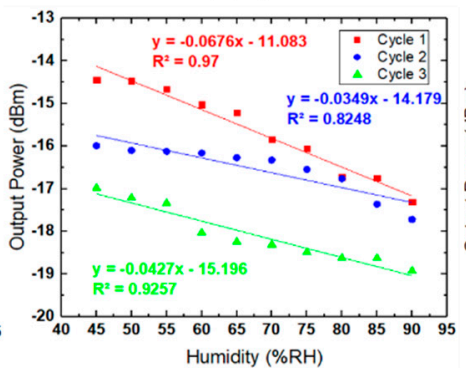

(e) $5 \mu \mathrm{m}$

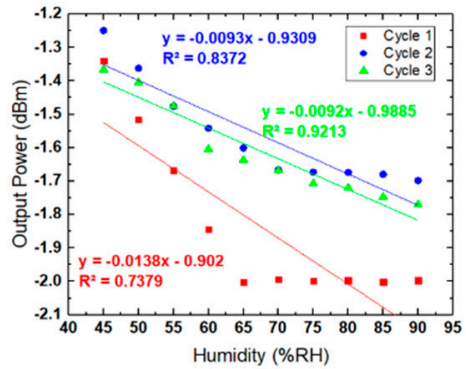

(c) $10 \mu \mathrm{m}$

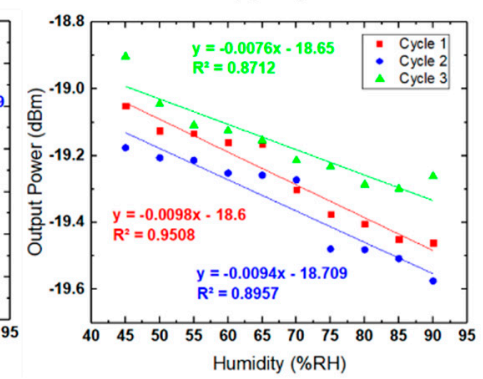

(f) $10 \mu \mathrm{m}$

Figure 9. Non-coated MF (a-c) and coated MF (d-f) of 2, 5, and $10 \mu \mathrm{m}$ repeatability results with different levels of humidity.

\section{Conclusions}

In this paper, we demonstrated the performance of tungsten disulphide $\left(\mathrm{WS}_{2}\right)$ as a coating material on tapered MF for RH sensing applications. We used it to enhance sensitivity with changing RH. The MF was formed with three different waist diameter sizes, i.e., 2, 5, and $10 \mu \mathrm{m}$, using a flame brushing technique developed in-house. The fabricated MFs were then prepared in two sets, non-coated and MFs coated with $\mathrm{WS}_{2}$; each set had a similar size of tapered region. Both sets were experimentally characterized using TLS with wavelength ranging from 1550 to $1550.1 \mathrm{~nm}$ with a step interval of $0.001 \mathrm{~nm}$. For these experiments with $45-90 \% \mathrm{RH}$, the results were compared and evaluated. The sensitivity and linearity parameters were analyzed to identify the sensing performance. The optimum performance was recorded for the $\mathrm{WS}_{2}$-coated $2 \mu \mathrm{m} \mathrm{MF}$ with sensitivity and linearity values of $0.0861 \mathrm{~dB} / \% \mathrm{RH}$ and $99.8 \%$, respectively. These results show the potential of $\mathrm{WS}_{2}$ to become the potential sensing material for optical sensing applications.

Author Contributions: Conceptualization, N.A. (Norazida Ali); methodology, N.A. (Norazida Ali) and S.R.A.; validation, S.R.A. and N.A. (Norhana Arsad); formal analysis, N.A. (Norazida Ali), N.A. (Norhana Arsad), M.A.M.J., H.R., M.I.M.A.K. and M.Z.A.R.; investigation, N.A. (Norazida Ali) and S.R.A.; writing-original draft preparation, N.A. (Norazida Ali); writing-review and editing, M.A.M.J., H.R., M.I.M.A.K., M.Z.A.R., Z.C. and N.M.; visualization, M.A.M.J.; supervision, N.A. (Norhana Arsad). All authors have read and agreed to the published version of the manuscript.

Funding: This research was funded by the Universiti Kebangsaan Malaysia under Modal Insan funding with grant code MI-2020-002, GUP-2019-010; the Royal Society of the UK under the Newton Fund with grant code IF026-2018; the University of Malaya with grant code IIRG028C-2019; and Kementerian Sains, Teknologi dan Inovasi (MOSTI), with grant code IF0419IF1082.

Institutional Review Board Statement: Not applicable.

Informed Consent Statement: Not applicable.

Data Availability Statement: Not applicable.

Acknowledgments: The authors would like to sincerely acknowledge Sulaiman Wadi Harun's infrastructure and support from the Department of Electrical Engineering, Faculty of Engineering, University of Malaya.

Conflicts of Interest: The authors declare no conflict of interest. 


\section{References}

1. Matsumoto, A.; Ohba, H.; Toshimitsu, M.; Akaoka, K.; Ruas, A.; Sakka, T.; Wakaida, I. Fiber-optic laser-induced breakdown spectroscopy of zirconium metal in air: Special features of the plasma produced by a long-pulse laser. Spectrochim. Acta-Part B At. Spectrosc. 2018, 142, 37-49. [CrossRef]

2. Zhao, J.; Li, L.; Zhao, L.; Tang, D.; Shen, D. Cavity-birefringence-dependent h-shaped pulse generation in a thulium-holmiumdoped fiber laser. Opt. Lett. 2018, 43, 247. [CrossRef] [PubMed]

3. Salim, M.A.M.; Ali, N.; Azzuhri, S.R.; Khudus, M.I.M.A.; Jamaludin, J.; Faruki, M.J.; Amiri, I.S. Switchable erbium-doped fiber laser (EDFL) using non-adiabatic microfiber. Opt. Fiber Technol. 2019, 52, 101967. [CrossRef]

4. He, C.; Fang, J.; Zhang, Y.; Yang, Y.; Yu, J.; Zhang, J.; Guan, H.; Qiu, W.; Wu, P.; Dong, J.; et al. High performance all-fiber temperature sensor based on coreless side-polished fiber wrapped with polydimethylsiloxane. Opt. Express 2018, 26, 9686-9699. [CrossRef]

5. He, Y.; Li, Y.; Li, N. Temperature-independent evanescent wave sensor made of a stress-released silica optical fiber taper. Opt. Fiber Technol. 2017, 36, 237-244. [CrossRef]

6. Yang, M.; Xiong, X.; He, R.; Luo, Y.; Tang, J.; Dong, J.; Lu, H.; Yu, J.; Guan, H.; Zhang, J.; et al. Halloysite Nanotube-Modified Plasmonic Interface for Highly Sensitive Refractive Index Sensing. ACS Appl. Mater. Interfaces 2018, 10, 5933-5940. [CrossRef] [PubMed]

7. Polley, N.; Basak, S.; Hass, R.; Pacholski, C. Fiber optic plasmonic sensors: Providing sensitive biosensor platforms with minimal lab equipment. Biosens. Bioelectron. 2019, 132, 368-374. [CrossRef]

8. Ng, W.P.; Lalam, N.; Dai, X.; Wu, Q.; Fu, Y.Q.; Harrington, P.; Gomes, N.J.; Lu, C. Integrating Radio-Over-Fiber Communication System and BOTDR Sensor System. Sensors 2020, 20, 2232. [CrossRef] [PubMed]

9. Fu, H.; Jiang, Y.; Ding, J.; Zhang, J.; Zhang, M.; Zhu, Y.; Li, H. Zinc oxide nanoparticle incorporated graphene oxide as sensing coating for interferometric optical microfiber for ammonia gas detection. Sens. Actuators B Chem. 2018, 254, 239-247. [CrossRef]

10. Zhou, N.; Wang, P.; Shi, Z.X.; Gao, Y.X.; Yang, Y.X.; Wang, Y.P.; Xie, Y.; Cai, D.W.; Guo, X.; Zhang, L.; et al. Au nanorod-coupled microfiber optical humidity sensors. Opt. Express 2019, 27, 8180. [CrossRef]

11. Johari, M.A.M.; Khudus, M.I.M.A.; Jali, M.H.; Maslinda, M.S.; Ali, U.U.M.; Harun, S.W.; Zaidan, A.H.; Apsari, R.; Yasin, M. Effect of tapering diameters with microbottle resonator for formaldehyde (CH2O) liquid sensing. Sens. Bio-Sens. Res. 2019, $25,100292$. [CrossRef]

12. Roriz, P.; Silva, S.; Frazão, O.; Novais, S. Optical fiber temperature sensors and their biomedical applications. Sensors 2020, 20, 2113. [CrossRef]

13. Jivraj, J.; Chen, C.; Huang, Y.; Ramjist, J.; Lu, Y.; Vuong, B.; Gu, X.; Yang, V.X.D. Smart laser osteotomy: Integrating a pulsed $1064 \mathrm{~nm}$ fiber laser into the sample arm of a fiber optic 1310nm OCT system for ablation monitoring. Biomed. Opt. Express 2018, 9 , 6374. [CrossRef] [PubMed]

14. Idris, S.; Azeman, N.H.; Noor Azmy, N.A.; Ratnam, C.T.; Mahdi, M.A.; Ahmad, A.A. Gamma irradiated Py/PVA for GOx immobilization on tapered optical fiber for glucose biosensing. Sens. Actuators B Chem. 2018, 273, 1404-1412. [CrossRef]

15. Spillman, W.B.; McMahon, D.H. Frustrated-total-internal-reflection multimode fiber-optic hydrophone. Appl. Opt. 1980, 19, 113-117. [CrossRef] [PubMed]

16. Brambilla, G.; Jung, Y.; Renna, F. Optical fiber microwires and nanowires manufactured by modified flame brushing technique: Properties and applications. Front. Optoelectron. China 2010, 3, 61-66. [CrossRef]

17. Jasim, A.A.; Harun, S.W.; Arof, H.; Ahmad, H. Inline Microfiber Mach-Zehnder Interferometer for High Temperature Sensing. IEEE Sens. J. 2013, 13, 626-628. [CrossRef]

18. Wu, X.; Tong, L. Optical microfibers and nanofibers. Nanophotonics 2013, 2, 407-428. [CrossRef]

19. Jali, M.H.; Rahim, H.R.A.; Johari, M.A.M.; Hamid, S.S.; Yusof, H.H.M.; Thokchom, S.; Wang, P.; Harun, S.W. Optical characterization of different waist diameter on microfiber loop resonator humidity sensor. Sens. Actuators A Phys. 2019, 285, 200-209. [CrossRef]

20. Kowsari, A.; Ahmadi, V.; Darvish, G.; Moravvej-Farshi, M.K. Dynamic analysis of optical microfiber coil resonators. Appl. Opt. 2016, 55, 6680. [CrossRef]

21. Han, Y.-G. Relative humidity sensors based on microfiber knot resonators-A review. Sensors 2019, 19, 5196. [CrossRef] [PubMed]

22. Pongruengkiat, W.; Pechprasarn, S. Whispering-gallery mode resonators for detecting cancer. Sensors 2017, 17, 2095. [CrossRef] [PubMed]

23. Zhang, D.; Guan, H.; Zhu, W.; Yu, J.; Lu, H.; Qiu, W.; Dong, J.; Zhang, J.; Luo, Y.; Chen, Z. All light-control-light properties of molybdenum diselenide (MoSe2)-coated-microfiber. Opt. Express 2017, 25, 28536. [CrossRef]

24. Guan, H.; Xia, K.; Chen, C.; Luo, Y.; Tang, J.; Lu, H.; Yu, J.; Zhang, J.; Zhong, Y.; Chen, Z. Tungsten disulfide wrapped on micro fiber for enhanced humidity sensing. Opt. Mater. Express 2017, 7, 1686. [CrossRef]

25. Talataisong, W.; Ismaeel, R.; Brambilla, G. A review of microfiber-based temperature sensors. Sensors 2018, 18, 461. [CrossRef]

26. Rosol, A.H.A.; Mahyuddin, M.B.H.; Jusoh, Z.; Harun, A.S.W. Tungsten disulfide saturable absorber for nanosecond pulses generation. Nonlinear Opt. Quantum Opt. 2019, 51, 161-169.

27. Xiong, Y.; Chen, H.W.; Zhang, D.W.; Zhou, P. Electronic and Optoelectronic Applications Based on ReS2. Phys. Status Solidi-Rapid Res. Lett. 2019, 13, 1-14. [CrossRef] 
28. Rashid, H.; Ramli, R.; Ahmad, H. Optoelectronic characteristics of tungsten disulphide based visible range photodetector. In Proceedings of the 2019 IEEE 9th International Nanoelectronics Conferences (INEC), Kuching, Malaysia, 3-5 July $2019 ;$; pp. 3-7. [CrossRef]

29. Luo, Y.; Chen, C.; Xia, K.; Peng, S.; Guan, H.; Tang, J.; Lu, H.; Yu, J.; Zhang, J.; Xiao, Y.; et al. Tungsten disulfide (WS2) based all-fiber-optic humidity sensor. Opt. Express 2016, 24, 8956. [CrossRef]

30. Faruki, M.J.; Ab Razak, M.Z.; Azzuhri, S.R.; Rahman, M.T.; Soltanian, M.R.K.; Brambilla, G.; Rahman, B.M.A.; Grattan, K.T.V.; De La Rue, R.; Ahmad, H. Effect of titanium dioxide $\left(\mathrm{TiO}_{2}\right)$ nanoparticle coating on the detection performance of microfiber knot resonator sensors for relative humidity measurement. Mater. Express 2016, 6, 501-508. [CrossRef]

31. Adnan Zain, H.; Hafiz Jali, M.; Rafis Abdul Rahim, H.; Ashadi Md Johari, M.; Helmi Mohd Yusof, H.; Thokchom, S.; Yasin, M.; Wadi Harun, S. ZnO nanorods coated microfiber loop resonator for relative humidity sensing. Opt. Fiber Technol. 2020, 54, 102080. [CrossRef]

32. Hazarika, S.J.; Mohanta, D. Inorganic fullerene-type WS2 nanoparticles: Processing, characterization and its photocatalytic performance on malachite green. Appl. Phys. A Mater. Sci. Process. 2017, 123, 381. [CrossRef]

33. Azzuhri, S.R.; Amiri, I.S.; Zulkhairi, A.S.; Salim, M.A.M.; Razak, M.Z.A.; Khyasudeen, M.F.; Ahmad, H.; Zakaria, R.; Yupapin, P. Application of graphene oxide based Microfiber-Knot resonator for relative humidity sensing. Results Phys. 2018, 9, 1572-1577. [CrossRef]

34. Sun, L.; Semenova, Y.; Wu, Q.; Liu, D.; Yuan, J.; Sang, X.; Yan, B.; Wang, K.; Yu, C.; Farrell, G. Investigation of humidity and temperature response of a silica gel coated microfiber coupler. IEEE Photonics J. 2016, 8, 1-7. [CrossRef]

35. Berkdemir, A.; Gutiérrez, H.R.; Botello-Méndez, A.R.; Perea-López, N.; Elías, A.L.; Chia, C.I.; Wang, B.; Crespi, V.H.; López-Urías, F.; Charlier, J.C.; et al. Identification of individual and few layers of WS2 using Raman Spectroscopy. Sci. Rep. 2013, 3, 1-8. [CrossRef]

36. Lee, C.Y.; Lee, G. Bin Humidity sensors: A review. Sens. Lett. 2005, 3, 1-15. [CrossRef]

37. Yusoff, S.F.A.Z.; Lim, C.S.; Azzuhri, S.R.; Ahmad, H.; Zakaria, R. Studies of Ag/ $\mathrm{TiO}_{2}$ plasmonics structures integrated in side polished optical fiber used as humidity sensor. Results Phys. 2018, 10, 308-316. [CrossRef] 